OPEN ACCESS

Edited by:

Sara María Soto,

ISGlobal, Spain

Reviewed by:

Dipankar Ghosh

Jawaharlal Nehru University, India

Nasib Singh,

Eternal University, India

*Correspondence:

Ramasare Prasad

girish.chandra8@gmail.com;

jrapdyfbs@iitr.ac.in

Specialty section:

This article was submitted to

Infectious Diseases,

a section of the journal

Frontiers in Microbiology

Received: 29 June 2017 Accepted: 20 October 2017 Published: 07 November 2017

Citation:

Kumari P, Mishra R, Arora N, Chatrath A, Gangwar R, Roy P and Prasad $R$ (2017) Antifungal and Anti-Biofilm Activity of Essential Oil

Active Components against

Cryptococcus neoformans and

Cryptococcus laurentii.

Front. Microbiol. 8:2161.

doi: 10.3389/fmich.2017.02161

\section{Antifungal and Anti-Biofilm Activity of Essential Oil Active Components against Cryptococcus neoformans and Cryptococcus laurentii}

\author{
Poonam Kumari ${ }^{1}$, Rutusmita Mishra ${ }^{2}$, Neha Arora $^{3}$, Apurva Chatrath ${ }^{1}$, Rashmi Gangwar ${ }^{1}$, \\ Partha Roy ${ }^{2}$ and Ramasare Prasad ${ }^{1 *}$ \\ ${ }^{1}$ Molecular Biology and Proteomics Laboratory, Department of Biotechnology, Indian Institute of Technology, Roorkee, India, \\ ${ }^{2}$ Molecular Endocrinology Laboratory, Department of Biotechnology, Indian Institute of Technology, Roorkee, India, \\ ${ }^{3}$ Molecular Microbiology Laboratory, Department of Biotechnology, Indian Institute of Technology, Roorkee, India
}

Cryptococcosis is an emerging and recalcitrant systemic infection occurring in immunocompromised patients. This invasive fungal infection is difficult to treat due to the ability of Cryptococcus neoformans and Cryptococcus laurentii to form biofilms resistant to standard antifungal treatment. The toxicity concern of these drugs has stimulated the search for natural therapeutic alternatives. Essential oil and their active components (EO-ACs) have shown to possess the variety of biological and pharmacological properties. In the present investigation the effect of six (EO-ACs) sourced from Oregano oil (Carvacrol), Cinnamon oil (Cinnamaldehyde), Lemongrass oil (Citral), Clove oil (Eugenol), Peppermint oil (Menthol) and Thyme oil (thymol) against three infectious forms; planktonic cells, biofilm formation and preformed biofilm of C. neoformans and C. laurentii were evaluated as compared to standard drugs. Data showed that antibiofilm activity of the tested EO-ACs were in the order: thymol $>$ carvacrol $>$ citral $>$ eugenol=cinnamaldehyde $>$ menthol respectively. The three most potent EO-ACs, thymol, carvacrol, and citral showed excellent antibiofilm activity at a much lower concentration against $C$. laurentii in comparison to $C$. neoformans indicating the resistant nature of the latter. Effect of the potent EO-ACs on the biofilm morphology was visualized using scanning electron microscopy (SEM) and confocal laser scanning microscopy (CLSM), which revealed the absence of extracellular polymeric matrix (EPM), reduction in cellular density and alteration in the surface morphology of biofilm cells. Further, to realize the efficacy of the EO-ACs in terms of human safety, cytotoxicity assays and co-culture model were evaluated. Thymol and carvacrol as compared to citral were the most efficient in terms of human safety in keratinocyte- Cryptococcus sp. co-culture infection model suggesting that these two can be further exploited as cost-effective and non-toxic anti-cryptococcal drugs.

Keywords: Cryptococcus neoformans, Cryptococcus laurentii, biofilm, EO-ACs, SEM, CLSM 


\section{INTRODUCTION}

Cryptococcosis caused by encapsulated basidiomycetes yeast Cryptococcus species is an opportunistic fungal infection prominent in the immunocompromised individuals (Martinez and Casadevall, 2015). Among the Cryptococcus sp., Cryptococcus neoformans remains the major causative agent, however, in the past decade, non-neoformans species such as Cryptococcus laurentii and Cryptococcus albidus have also been reported to be responsible for 80 percent of the infection (Khawcharoenporn et al., 2007). The need to address the problem of cryptococcosis has significantly increased in past years due to acquired immunodeficiency syndrome (AIDS) epidemic, intensive chemotherapy of cancer patients, solid organ transplant recipients, intravenous drug users and extensive use of immunosuppressive drugs (Kronstad et al., 2011; Shorman et al., 2016). It has been reported that the global burden of cryptococcosis is over one million cases annually, resulting in nearly 625,000 deaths per year (Park et al., 2009). According to United Nations Programme on HIV and AIDS (UNAIDS) report (2016), India has the third largest HIV epidemics (0.26\%) in the world with an estimated 68,000 deaths per year. Among the HIV/AIDS patients in Northern India, 3.3\% were reported to have cryptococcal infections while in Central India, 3.2\% Eucalyptus trees and soil with avian excreta were colonized by C. neoformans. Further, from 2005 to 2013, 117 cases of cryptococcosis were reported in Southern India including $87 \%$ in HIV positive patients (Berger, 2017).

The ecological strategy that has been associated with such a chronic infection caused by C. neoformans, is the formation of biofilm (Ramage and Williams, 2013). A major component of its polysaccharide capsule, glucuronoxylomannan (GXM), plays a central role in biofilm formation and its pathogenesis (Martinez and Casadevall, 2005). The selfproduced polysaccharide rich extracellular polymeric matrix (EPM) of biofilm makes the sessile cryptococcal cells resistant to standard antimicrobial therapy resulting in fungal resistance. These biofilm-associated cryptococcal cells are also protected from macrophage phagocytosis in tissues thereby enhancing its quorum sensing and survival (Aslanyan et al., 2017). Some cases of C. neoformans and C. laurentii forming biofilm have been associated with the ventriculoatrial shunt, indwelling intravascular catheters, cardiac valve and peritoneal dialysis fistula (Ajesh and Sreejith, 2012; Martinez and Casadevall, 2015). This high resistance of biofilm to antifungal drugs compared to their planktonic counterparts is therefore of great clinical relevance (Rizk et al., 2004). For example, Cryptococcus sp. biofilm are highly resistant to azole antifungals while amphotericin B and its lipid formulations show good efficacy against biofilm form, however the effective concentrations are above the therapeutic range; thus leading to severe toxicity, renal dysfunction, resulting in the emergence of drug-resistant strains (Brouwer et al., 2004; Delattin et al., 2014). Therefore, it is crucial to develop new drugs and alternative natural therapies that are potentially active against Cryptococcus sp. planktonic and its biofilm form.
Phytochemicals including essential oils (EO) and plant extracts isolated from diverse flora have shown to be effective alternatives with a potential to form novel drugs that could effectively be used in the treatment of such kind of recalcitrant infections (Bakkali et al., 2008). The EO and its active components (EO-ACs) have been extensively exploited and described to have antimicrobial, anti-inflammatory and antioxidant activities and considered safe in terms of animal and human health usage (Tampieri et al., 2005; Alves-Silva et al., 2016; Darwish et al., 2016). According to a recent report, carvacrol showed antifungal activity against $C$. neoformans strains and thus could be a potent drug component (Nobrega et al., 2016).

The previous studies in this field have majorly focused on the planktonic form, leaving behind a lacuna in the activity of EOACs against recalcitrant Cryptococcus biofilms. With the objective of filling the said lacuna the present study investigated the effect of essential oil active components (EO-ACs) such as terpenic phenol (thymol, carvacrol, and eugenol); terpenic aldehydes (citral, cinnamaldehyde), and terpenic alcohol (menthol) against C. neoformans and C. laurentii biofilm formation and preformed biofilms. Moreover, the study pursued to elaborate the effect of the above mentioned terpenic compounds on the cell surfaces and consequent micromorphological changes occurring in the cryptococcal cells. Further, the safety of the effective EO-ACs for the treatment of cutaneous and systemic cryptococcosis was validated by assessing the cytotoxicity of EO-ACs on human keratinocytes and human renal cells along with their efficacy in the co-culture model.

\section{MATERIALS AND METHODS}

\section{Essential Oil Active Components (EO-ACs) and Standard Antifungal}

The EO-ACs [citral, cinnamaldehyde, menthol, thymol, and eugenol], standard drugs [amphotericin B, nystatin, and fluconazole], were commercially obtained from Sigma-Aldrich, USA. A stock solution of EO-ACs and standard drugs were prepared in dimethylsulfoxide (DMSO, HiMedia, India).

\section{Fungal Strains and Growth Conditions}

Two reference strains C. neoformans (NCIM 3541) and C. laurentii (NCIM 3373) used in the present investigation, were obtained from National Collection of Industrial Microorganism, Pune. Both the strains were cultured on Sabouraud dextrose agar (SDA, HiMedia, India) for $48 \mathrm{~h}$ at $30^{\circ} \mathrm{C}$ and subcultured monthly. Glycerol stock of the strains was prepared in Sabouraud dextrose broth (SDB, HiMedia, India) and frozen at $-80^{\circ} \mathrm{C}$. All the experiments were performed in compliance with Biosafety Level 2 (BSL-2) guidelines.

\section{EO-ACs Susceptibility Testing}

EO-ACs activity against planktonic cells of both the Cryptococcus species was performed by standard broth microdilution method recommended by Clinical and Laboratory Standards Institute (CLSI, 2008) reference protocols M27-A3, with a modification of replacing RPMI 1640 medium by Yeast Nitrogen Base (YNB, HiMedia, India). Planktonic cells grown in SDB were harvested 
at exponential phase, washed with sterile $1 \mathrm{X}$ phosphate-buffered saline (PBS $\mathrm{pH} 7,0.1 \mathrm{M}$ ) and re-suspended in YNB medium at a density of $1-5 \times 10^{4}$ cells $/ \mathrm{mL}$. Serially double diluted concentration of EO-ACs/drugs $(0-1,024 \mu \mathrm{g} / \mathrm{mL})$ were added in 96-well microtiter plates to provide $0.5-2.5 \times 10^{4}$ cells $/ \mathrm{mL}$ in $200 \mu \mathrm{L}$ working volume. YNB medium with $1 \%$ DMSO plus $10 \%$ mineral oil (HiMedia) was added to control wells (Fontenelle et al., 2007). Tween-80 (HiMedia, India) at $0.05 \%$ $(\mathrm{v} / \mathrm{v})$ final concentration was added in all assays to enhance EO-ACs solubility. The plates were then incubated at $30^{\circ} \mathrm{C}$ for $24 \mathrm{~h}$ without shaking. After incubation, the growth of cells was measured by microtiter plate reader (SpectraMax, Molecular Devices, USA) at $530 \mathrm{~nm}$ and Minimum inhibitory concentration $\left(\mathrm{MIC}_{80}\right)$ which reduces $80 \%$ cell growth as compared to control (without EO-ACs/drugs) was determined.

\section{Biofilm Formation and Its Metabolic Activity}

Biofilm formation was initiated by culturing C. neoformans and C. laurentii strains in SDB for $24 \mathrm{~h}$ in an incubator shaker at $30^{\circ} \mathrm{C}$ with $150 \mathrm{rpm}$. After centrifugation the pellet was washed twice with PBS, followed by counting cells using a haemocytometer, and then suspended at $10^{8}$ cells $/ \mathrm{mL}$ in minimal medium $(20$

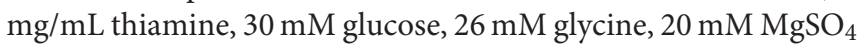

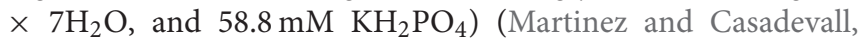
2005). The cell suspension $(100 \mu \mathrm{L})$ was then added into fetal bovine serum (FBS, Gibco, United States) pre-treated wells of polystyrene 96-well plates (Tarsons, India) and incubated at $30^{\circ} \mathrm{C}$ without shaking for $2 \mathrm{~h}$ for the adhesion of the cells. Biofilms were allowed to form over a series of time intervals $(2,4,8,24$, 48 , and $72 \mathrm{~h}$ ) with shaking at $70 \mathrm{rpm}$. After incubation, the wells containing Cryptococcus biofilms were washed thrice with $0.05 \%$ Tween 20 (HiMedia, India) in PBS to remove non-adherent cryptococcal cells. The cells that still remained attached to the polystyrene surface were considered as true biofilm. All assays were carried out in triplicates.

The biofilm formation was measured using XTT (2,3-Bis-(2-Methoxy-4-Nitro-5-Sulfophenyl)-2H-Tetrazolium5-Carboxanilide) reduction assay (Martinez and Casadevall, 2005). Filter sterilized stock solution ( $0.5 \mathrm{~g} / \mathrm{L})$ of XTT tetrazolium salt (Sigma-Aldrich, USA) in 1X PBS was stored in aliquots at $-80^{\circ} \mathrm{C}$. Preceding assay, an aliquot was thawed and $1 \mu \mathrm{M}$ freshly prepared menadione (Sigma-Aldrich, Germany) was then added to the XTT solution. The volume of $100 \mu \mathrm{L}$ of XTT-menadione solution was added into the wells with prewashed biofilm and without biofilm. The plates were then incubated at $37^{\circ} \mathrm{C}$ for a period of $4 \mathrm{~h}$ in dark. Colorimetric reduction of XTT was measured at $492 \mathrm{~nm}$ using microtiter plate reader. The biofilm formation was also assessed using a light microscope (Zeiss, Axiovert 25, Germany).

\section{Effect of EO-ACs Against Cryptococcus sp. Biofilm Formation and Preformed Biofilms}

The biofilm formation assay was performed in 96-well microtiter plates according to the protocol described by Martinez and Casadevall (2006). In brief, the cell suspension was prepared in minimal medium at a density of $2 \times 10^{8}$ cells $/ \mathrm{mL}$ and dispensed into the wells of microtiter plates. Serially doublediluted concentrations of EO-ACs/drugs $(0-1,024 \mu \mathrm{g} / \mathrm{mL})$ in minimal medium were added to the wells to attain the final cell density of $1 \times 10^{8}$ cells $/ \mathrm{mL}$ for biofilm formation and plates were incubated at $30^{\circ} \mathrm{C}$ for $48 \mathrm{~h}$. Subsequently, quantification of biofilms was performed by colorimetric XTT reduction assay and the biofilm inhibiting concentration $\left(\mathrm{BIC}_{80}\right)$, the lowest concentration of EO-ACs/drugs that inhibits $80 \%$ metabolic activity of biofilm formation as compared to control (EO-ACs/drugs-free) were determined. For preformed biofilm assay, the biofilm was made as described in previous section (Martinez and Casadevall, 2006). Thereafter, serially doublediluted concentrations of EO-ACs/drugs $(0-1,024 \mu \mathrm{g} / \mathrm{mL})$ were added into the wells of prewashed and preformed biofilms. Minimal medium containing $1 \%$ DMSO plus $10 \%$ mineral oil without EO-ACs/drugs served as negative control. The microtiter plates were then incubated at $30^{\circ} \mathrm{C}$ for $48 \mathrm{~h}$, followed by quantification with colorimetric XTT reduction assay and the biofilm-eradicating concentration $\left(\mathrm{BEC}_{80}\right)$, the lowest concentration of EO-ACs/drugs that eradicates $80 \%$ of biofilm compared to negative control were calculated.

\section{Scanning Electron Microscopy (SEM) and Confocal Laser Scanning Microscopy (CLSM) Analysis of C. neoformans and C. laurentii Biofilm}

The effect of thymol, carvacrol, and citral and the standard drug (amphotericin B) on biofilms were qualitatively analyzed by scanning electron microscopy (SEM) and confocal laser scanning microscopy (CLSM). Biofilms were formed on $20 \%$ fetal bovine serum (FBS, Gibco, United States) treated pre-sterilized polystyrene disc $\left(1 \mathrm{~mm}^{2}\right)$ in 12-well cell culture plate (Tarsons, India) in the presence of respective $\mathrm{BIC}_{80}$ of the above $\mathrm{EO}$ ACs/drug (Martinez and Casadevall, 2007). The cell culture plates were incubated at $30^{\circ} \mathrm{C}$ for $48 \mathrm{~h}$. Minimum media containing $1 \%$ DMSO plus $10 \%$ mineral oil without EO-ACs was included as a negative control and amphotericin B treated biofilm served as positive control. At the end of incubation, polystyrene discs were transferred to new 12-well plates and washed thrice with PBS. For SEM, biofilm was washed with PBS and subsequently fixed for $2 \mathrm{~h}$ by glutaraldehyde $(2.5 \% \mathrm{v} / \mathrm{v})$ in PBS $(0.1 \mathrm{M}, \mathrm{pH} 7.5)$, followed by dehydration in 30,50,70, 90, and $100 \%$ ethanol solutions. The samples were then dried and sputtered with gold and visualized under scanning electron microscope (Carl Zeiss AG, EVO 40) in high-vacuum mode at $20 \mathrm{kV}$. Confocal microscopy was performed according to Martinez and Casadevall (2006). For CLSM, C. neoformans and C. laurentii biofilms were formed in the presence of 32 and $16 \mu \mathrm{g} / \mathrm{mL}$ EO-ACs respectively. Control and treated biofilms were incubated for $45 \mathrm{~min}$ at $37^{\circ} \mathrm{C}$ in $75 \mu \mathrm{L}$ of PBS containing the fluorescent probes FUN-1 $(10 \mu \mathrm{M}$, Molecular Probes, USA) and Concanavalin A conjugated to Alexa Fluor 488, (CAAF 488, $25 \mu$ M, Molecular Probes, USA). Confocal microscopic examinations of biofilms on polystyrene discs were performed using a Zeiss Axiovert $200 \mathrm{M}$ inverted microscope and the images were analyzed with Zen software. 


\section{Cytotoxicity of EO-ACs in Normal Human Cell Lines}

Human keratinocyte cell line (HaCaT) and Human embryonic kidney cells (HEK-293) (National Center for Cell Sciences, Pune) were cultured in Dulbecco's modified Eagle's Medium (DMEM, Gibco, United States) supplemented with 10\% FBS and $1 \%$ antibiotics (Penicillin/streptomycin) solution and kept in a humidified $5 \% \mathrm{CO}_{2}$ incubator maintained at $37^{\circ} \mathrm{C}$. Initially $\mathrm{HaCaT}$ and HEK-293 were seeded at a density of $5 \times 10^{3}$ cells/well in 96 well plates. After $24 \mathrm{~h}$ of attachment, the cells were incubated in DMEM high glucose media supplemented with and without EO-ACs (thymol, carvacrol, and citral) prepared in DMSO at concentrations $(8-256 \mu \mathrm{g} / \mathrm{mL})$ to check their cytotoxic effect. DMSO $(0.1 \%)$ served as the negative control. After $24 \mathrm{~h}$ incubation at $37^{\circ} \mathrm{C}$, MTT [3-(4, 5-Dimethyl-2-thiazolyl)-2, 5diphenyltetrazolium bromide] assay was performed to measure the cell viability (Mohapatra et al., 2017). MTT (Sigma-Aldrich, USA) was added to the media at a working concentration of 0.5 $\mathrm{mg} / \mathrm{ml}$ and the cells were incubated in the $\mathrm{CO}_{2}$ incubator at $37^{\circ} \mathrm{C}$ further for $4 \mathrm{~h}$. Then, the media with MTT dye was aspirated from each well and the water insoluble formazan crystals formed were dissolved in $200 \mu \mathrm{L}$ DMSO directly added to each well of 96 well plates. The plates were placed in a shaker incubator for $30 \mathrm{~min}$ for complete dissolution of the formazan crystals. The absorbance value was recorded at $570 \mathrm{~nm}$ using Fluostar Optima Plate Reader (BMG Labtech, Germany). The percentage cell viability was estimated by the following formula:

Percentage Cell Viability $=($ Mean OD of treated cells /Mean OD of untreated cells) $\times 100$.

Subsequently, cytotoxic concentration $\left(\mathrm{CC}_{50}\right)$ at which the cell viability dropped by $50 \%$ was recorded.

\section{Bright-Field and Fluorescence Microscopic Analysis of HaCaT and HEK-293}

The effect of EO-ACs treatment on the morphology of the normal human cell lines was observed by employing brightfield microscopic imaging. Briefly, $5 \times 10^{5}$ cells/well $(\mathrm{HaCaT}$ and HEK293) were seeded in a 12 well plate and incubated for $24 \mathrm{~h}$ in a humidified $5 \% \mathrm{CO}_{2}$ incubator at $37{ }^{\circ} \mathrm{C}$ as described in the previous section. The human cells were then treated with the respective $\mathrm{MIC}_{80}$ concentration of the EO-ACs against C. neoformans. The plates were kept in the incubator further for $24 \mathrm{~h}$. After the treatment period was over, the morphology of the negative control cells and the EO-ACs treated cells were visualized under an inverted light microscope (Zeiss, Axiovert 25, Germany).

The cytotoxic effect and changes in the nuclear morphology due to the administration of EO-ACs were examined with Acridine Orange-Ethidium Bromide (AO-EB) dual staining dye mixture at a concentration $100 \mu \mathrm{g} / \mathrm{mL}$ in PBS (Kasibhatla et al., 2006). The images were captured using $40 \mathrm{X}$ objective lens under the fluorescence microscope (Zeiss, Axiovert 25, Germany) with 465 and $563 \mathrm{~nm}$ filters respectively.

\section{Efficacy of EO-ACs in Co-culture Model of Cryptococcus sp. and $\mathrm{HaCaT}$}

The co-culture was performed according to a previous study reported by Wong et al. (2014). HaCaT cell culture was performed as described above. The cells were incubated at $37^{\circ} \mathrm{C}$ in the presence of $5 \% \mathrm{CO}_{2}$ until confluence was reached with medium changed every day. The cells were washed once with PBS, and fresh medium without antibiotics (as antibiotics could inhibit Cryptococcus growth) was added. A cell suspension $(1 \times$ $10^{4} \mathrm{CFUs} / \mathrm{mL}$ ) of $C$. neoformans and C. laurentii was prepared in the growth medium DMEM (without antibiotics), and $100 \mu \mathrm{L}$ of each cell suspension was added into separate wells. Thymol, carvacrol, and citral were added at respective $\mathrm{MIC}_{80}$ against C. neoformans and C. laurentii whereas the untreated vehicle control contained only the growth medium with $0.1 \%$ DMSO. The plates were then incubated at $30^{\circ} \mathrm{C}$ for $24 \mathrm{~h}$ in the presence of $5 \% \mathrm{CO}_{2}$. The viability of $\mathrm{HaCaT}$ and cryptococcal cells were subsequently assessed under brightfield and AO-EB dual staining using fluorescence microscopy.

\section{Statistical Analysis}

All experiments were performed in triplicate. Data analysis was conducted using SigmaPlot 11.0 (Systat Software, San Jose, CA). The data are expressed as mean \pm standard deviations (SD) and statistical significance between treated and control groups was analyzed using One-way Analysis of Variance (ANOVA). Significant difference was defined as $p<0.05$. IC $_{50}$ values were evaluated using GraphPad Prism.

\section{RESULTS}

\section{Evaluating the Antifungal Activity of EO-ACs against Planktonic Cells of C. neoformans and C. laurentii}

In order to determine the efficacy of EO-ACs (thymol, carvacrol, eugenol, citral, cinnamaldehyde, and menthol) as compared to the standard antifungal drugs (amphotericin B, nystatin, and fluconazole) against C. neoformans and C. laurentii, the $\mathrm{MIC}_{80}$ values were determined. Data showed the planktonic (free-floating) form of C. neoformans and C. laurentii were more susceptible to polyene drugs (amphotericin B, nystatin) as compared to fluconazole (32 and $16 \mu \mathrm{g} / \mathrm{mL}$ ) (Table 1). The $\mathrm{MIC}_{80}$ of thymol, carvacrol, and citral against C. neoformans were found to be 16,32 , and $64 \mu \mathrm{g} / \mathrm{mL}$ while, C. laurentii showed $\mathrm{MIC}_{80}$ at 8,16 , and $32 \mu \mathrm{g} / \mathrm{mL}$ respectively (Table 1 ). Cinnamaldehyde and eugenol showed similar $\mathrm{MIC}_{80}$ value $(128 \mu \mathrm{g} / \mathrm{mL})$ against $C$. neoformans while C. laurentii was found to be more susceptible to cinnamaldehyde $(64 \mu \mathrm{g} / \mathrm{mL})$ in comparison to eugenol $(128 \mu \mathrm{g} / \mathrm{mL})$. Menthol was the least effective among all the tested EO-ACs against both the species (Table 1).

\section{Comparison of C. neoformans and C. laurentii Biofilm Formation}

The biofilm formation kinetics was performed up to $72 \mathrm{~h}$ time point to optimize and compare the time period for mature 
TABLE 1 | List of essential oil active components (EO-ACs) and standard drugs used in the susceptibility study against Cryptococcus neoformans and Cryptococcus laurentii and their respective $\mathrm{MIC}_{80}, \mathrm{BIC}_{80}$, and $\mathrm{BEC}_{80}$ values.

\begin{tabular}{|c|c|c|c|c|c|c|}
\hline \multirow[t]{2}{*}{ Cryptococcus spp. } & \multicolumn{3}{|c|}{ C. neoformans } & \multicolumn{3}{|c|}{ C. laurentii } \\
\hline & $\mathrm{MIC}_{80}$ & $\mathrm{BIC}_{80}^{\mathrm{a}}$ & $\mathrm{BEC}_{80}^{\mathrm{b}}$ & $\mathrm{MIC}_{80}$ & $\mathrm{BIC}_{80}$ & $\mathrm{BEC}_{80}$ \\
\hline \multicolumn{7}{|c|}{ STANDARD DRUGS $(\mu \mathrm{g} / \mathrm{ml})$} \\
\hline Amphotericin B & 1 & 4 & 32 & 0.5 & 2 & 16 \\
\hline Nystatin & 2 & 8 & 64 & 1 & 4 & 64 \\
\hline Fluconazole & 32 & 128 & $>1,024$ & 16 & 64 & $>1,024$ \\
\hline \multicolumn{7}{|l|}{ EO-AC $(\mu \mathrm{g} / \mathrm{ml})$} \\
\hline Thymol & 16 & 32 & 128 & 8 & 16 & 64 \\
\hline Eugenol & 128 & 256 & 512 & 128 & 256 & 512 \\
\hline Carvacrol & 32 & 64 & 256 & 16 & 32 & 128 \\
\hline Citral & 64 & 128 & 256 & 32 & 64 & 256 \\
\hline Cinnamaldehyde & 128 & 256 & 512 & 64 & 128 & 512 \\
\hline Menthol & 256 & 512 & $>1,024$ & 128 & 512 & $>1,024$ \\
\hline
\end{tabular}

$B I C_{80}^{a}$ and $B E C_{80}^{b}$ were determined by measuring XTT reduction activity.

biofilm formation for both the fungal species (Figure 1A). Interestingly both $C$. neoformans and $C$. laurentii shared a similar pattern of biofilm growth reaching maturation at $48 \mathrm{~h}$ with no significant difference in the metabolic activity rates up to $72 \mathrm{~h}$. However, between these two Cryptococcus sp; C. neoformans adhered faster as compared to C. laurentii during the early stage $(2-4 \mathrm{~h})$ in which the cells appeared individual; in a single layer pattern with recurrent budding (Figure 1B). Succeeding, the early phase of adhesion, uniformly distributed micro-colonies of yeast cells throughout the plastic support was observed representing the intermediate stage $(8 \mathrm{~h})$. Lastly, the maturation stage was observed at $48 \mathrm{~h}$ time point, where the cryptococcal cells were visualized to be in more complex arrangement displaying multi-layered compact structure with increase in the extracellular material surrounding the cell (Figure 1B).

\section{Determining the Effect of EO-ACs against Biofilm Formation and Preformed Biofilm}

The potential and efficacy of EO-ACs against biofilm formation and preformed biofilm was determined in terms of $\mathrm{BIC}_{80}$ and $\mathrm{BEC}_{80}$ respectively and the viability was expressed as percentage metabolic activity. The $\mathrm{BIC}_{80}$ of amphotericin $\mathrm{B}(4$, $2 \mu \mathrm{g} / \mathrm{mL})$; nystatin $(2 \mu \mathrm{g} / \mathrm{mL})$ and fluconazole $(128,64 \mu \mathrm{g} / \mathrm{mL})$ against $C$. neoformans and C. laurentii were 4 -fold higher than their planktonic MICs, demonstrating that biofilm-associated cryptococcal cells are substantially more resistant to drugs than their planktonic counterparts (Table 1). Among the EO-ACs, menthol showed the maximum $\mathrm{BIC}_{80}(512 \mu \mathrm{g} / \mathrm{mL})$ against both the Cryptococcus species (Figures 2A,B) while, thymol exhibited minimum $\mathrm{BIC}_{80}$ of 32 and $16 \mu \mathrm{g} / \mathrm{mL}$ respectively which was comparable with the standard drugs (Figures 3A,B). Eugenol prevented the biofilm formation at $256 \mu \mathrm{g} / \mathrm{mL}$, which was twice the MIC. Further, it was observed that effective concentration of citral and carvacrol against biofilm formation of C. laurentii was observed to be up to $50 \%$ less as compared to the potency of the same against C. neoformans biofilm formation (Table 1).

Moreover, on evaluating the efficacy of EO-ACs and standard drugs on preformed biofilms, the data showed that the polyene drugs inhibited the preformed biofilm at the concentration 16-fold higher than their respective $\mathrm{BIC}_{80}$ while fluconazole failed to eradicate biofilm even at the highest concentration tested demonstrating preformed biofilm resistance (Table 1). On the other hand, the $\mathrm{BEC}_{80}$ value of 256 and $512 \mu \mathrm{g} / \mathrm{mL}$ was recorded in biofilm treated with citral and cinnamaldehyde respectively. Menthol showed the minimum anti-biofilm activity and was unable to eradicate the biofilm even at the highest concentration of $1,024 \mu \mathrm{g} / \mathrm{mL}$ (Figures 2C,D). Furthermore, BEC $_{80}(128$ and $256 \mu \mathrm{g} / \mathrm{mL})$ of thymol and carvacrol against C. neoformans were 4-fold and 8-fold higher as compared to their biofilm forming planktonic cells and free-floating planktonic cells respectively (Figure 3C). The $\mathrm{BEC}_{80}(64$ and $128 \mu \mathrm{g} / \mathrm{mL}$ ) of thymol and carvacrol against $C$. laurentii was comparatively lower (Figure 3D). Citral was equally effective in eradicating preformed biofilms of both the species with $\mathrm{BEC}_{80}$ of $256 \mu \mathrm{g} / \mathrm{mL}$.

Overall these results suggest that the six tested EO-ACs exhibits anti-biofilm activity against $C$. neoformans and $C$. laurentii in the following order: thymol $>$ carvacrol $>$ citral $>$ eugenol $=$ cinnamaldehyde $>$ menthol respectively.

\section{Analyzing the Changes in Biofilm Cells Morphology after EO-ACs Treatment}

Based on the above $\mathrm{BIC}_{80}$ and $\mathrm{BEC}_{80}$ results, most potent $\mathrm{EO}$ ACs (Citral>Carvacrol>Thymol) were selected for visualizing the changes in the cell morphology of cryptococcal cells using SEM and Confocal Imaging. The scanning electron micrographs showed that the control cells at $0 \mathrm{~h}$ had smooth outer cell surface (Figures 5A,G) and untreated biofilm (48 h) exhibited agglomeration of cryptococcal cells with EPM (as indicated by the black arrows) (Figures 5B,H). However, on treatment of $C$. neoformans and C. laurentii biofilms at $\mathrm{BIC}_{80}$ of citral (128 and $64 \mu \mathrm{g} / \mathrm{mL}$ ), no visible EPM was detected along with significant reduction in the density of cells (Figures 5D,J). Citral also caused aberrations in the cell membrane resulting in the bursting of cells. Similarly, biofilm treated in the presence of $\mathrm{BIC}_{80}$ of carvacrol (64 and $32 \mu \mathrm{g} / \mathrm{mL}$ ) showed disruption with irregular cell surface and oozing out of cellular content (Figures 5E,K). Further, treatment of $C$. neoformans biofilm to $\mathrm{BIC}_{80}$ thymol against both the species, the biofilm formation was almost completely inhibited with only a few cells left. The shrinkage of the cells was also noticed (Figures 5F,L). In general, the SEM images of morphological alterations in cryptococcal cells in the presence of EO-ACs were comparable to those of the positive control group (amphotericin $\mathrm{B}, \mathrm{BIC}_{80}$ ) suggesting the efficacy of the above EO-ACs in inhibiting the growth of Cryptococcus sp. biofilms.

The visual effects on the biofilm structure and morphology were analyzed using FUN-1 and CAAF 488. In metabolically active cells, FUN-1 (excitation wavelength $=470 \mathrm{~nm}$; emission $=590 \mathrm{~nm}$ ) get converted into red cylindrical intravacuolar structure. CAAF 488 (excitation wavelength $=488 \mathrm{~nm}$; 
A
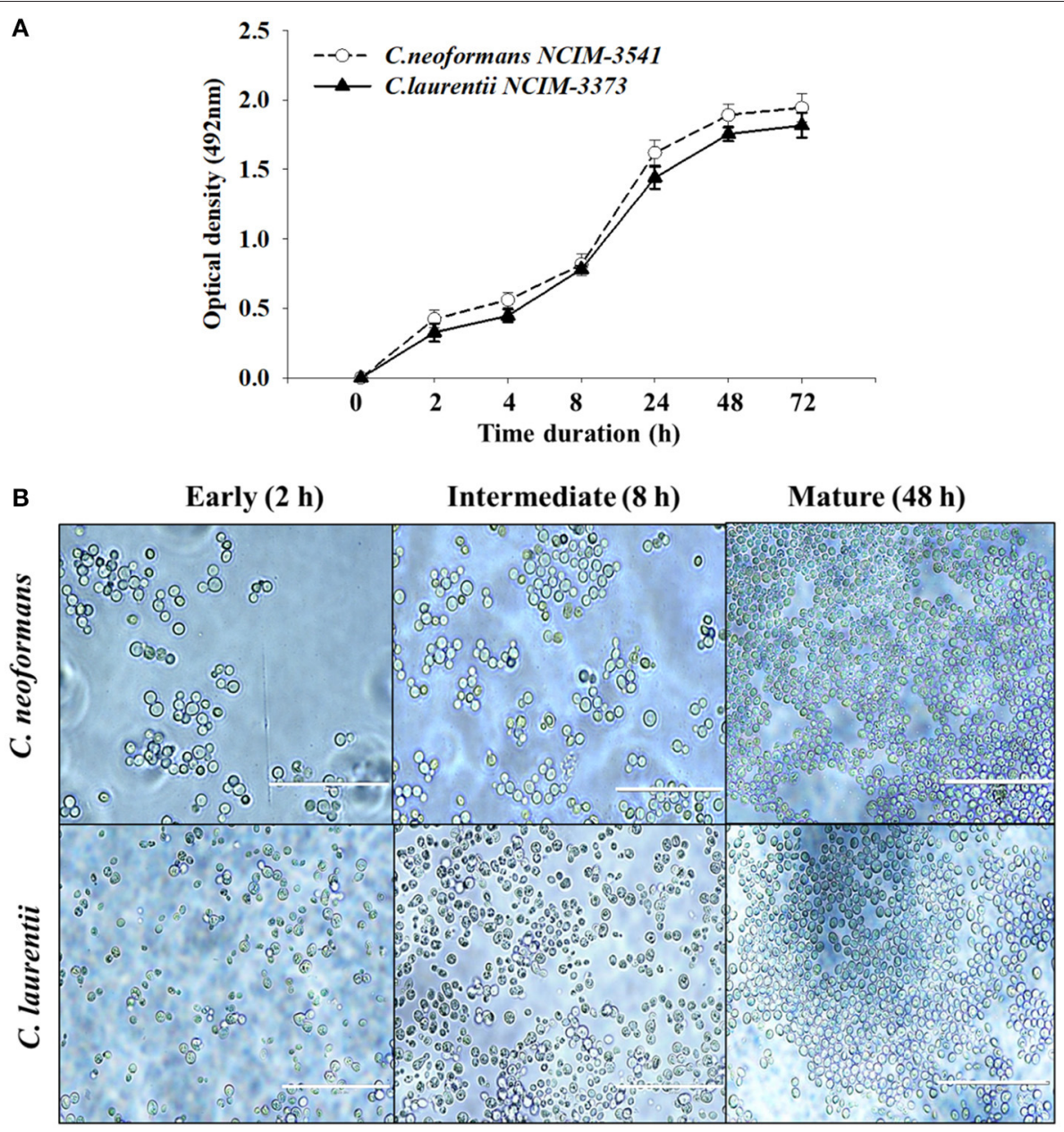

FIGURE 1 | Evaluation of Cryptococcus sp. biofilm formation. (A) Comparison of kinetics of Cryptococcus neoformans (NCIM 3541) and Cryptococcus laurentii (NCIM 3373) biofilm formation on polystyrene microtiter plates using colorimetric XTT reduction assay. Error bars represent standard deviation (SD). (B) Light microscopic images at different stages of biofilm formation. Images were captured using a 40X power field. Scale bar, $50 \mu \mathrm{m}$.

emission $=505 \mathrm{~nm}$ ) binds to glucose and mannose residues of the cell wall and capsule polysaccharides (EPM) and fluorescence green (Martinez and Casadevall, 2006). Regions of red fluorescence (FUN-1) correspond to live or viable cells while, the green fluorescence (CAAF-488) indicates cell wall or capsule polysaccharides, and yellow-brownish areas signify metabolically inactive or non-viable cells. The confocal micrographs of the mature C. neoformans biofilm (control) displayed a composite structure with a nexus of viable cells emitting red fluorescence along with EPM giving out green fluorescence (Figure 5A). On the other hand, biofilms treated with $32 \mu \mathrm{g} / \mathrm{mL}$ of citral was marked by a decrease in EPM and metabolic activity of cells as some area appeared yellowish brown, while carvacrol treated biofilm at the same concentration showed less number of cells and thymol treated cells showed nearly complete inhibition of biofilm with dead yeast cells (Figures 5B-D). The same pattern was also observed in case of C. laurentii biofilm but at a lower concentration of $16 \mu \mathrm{g} / \mathrm{mL}$ (Figures 5F-H).

\section{Assessing the Cytotoxicity of EO-ACs in Normal Human Cell Lines}

C. neoformans and C. laurentii causes disseminated cryptococcosis affecting organs like skin and kidney (ref). Therefore, in order to establish the non-toxicity of the above EO-ACs (thymol, carvacrol, and citral) on the normal human cell line, the cytotoxic activity was tested in HaCaT and HEK-293. The EO-ACs decreased cell viability in a concentrationdependent manner on both the cell lines. The results revealed that $\mathrm{CC}_{50}$ of thymol was $1,280 \pm 3.11 \mu \mathrm{g} / \mathrm{mL}$ and $283.65 \pm$ $2.45 \mu \mathrm{g} / \mathrm{mL}$ in $\mathrm{HaCaT}$ and HEK 293 respectively (Table 2). Further, treatment with thymol at $16 \mu \mathrm{g} / \mathrm{mL}$ reduced the viability of HEK-293 cells by $7.5 \%$ compared with the untreated controls (untreated), which was low as compared to citral (18.4\% reduction) (Figure 7A). Thymol and citral at $64 \mu \mathrm{g} / \mathrm{mL}$ caused 10.7 and $37.6 \%$ reduction in $\mathrm{HaCaT}$ cell viability compared to the controls, respectively (Figure 6A). However, carvacrol treatment reduced the viability of $\mathrm{HaCaT}$ and HEK-293 by 10.1 and $14.5 \%$ respectively as compared to the treatment free 

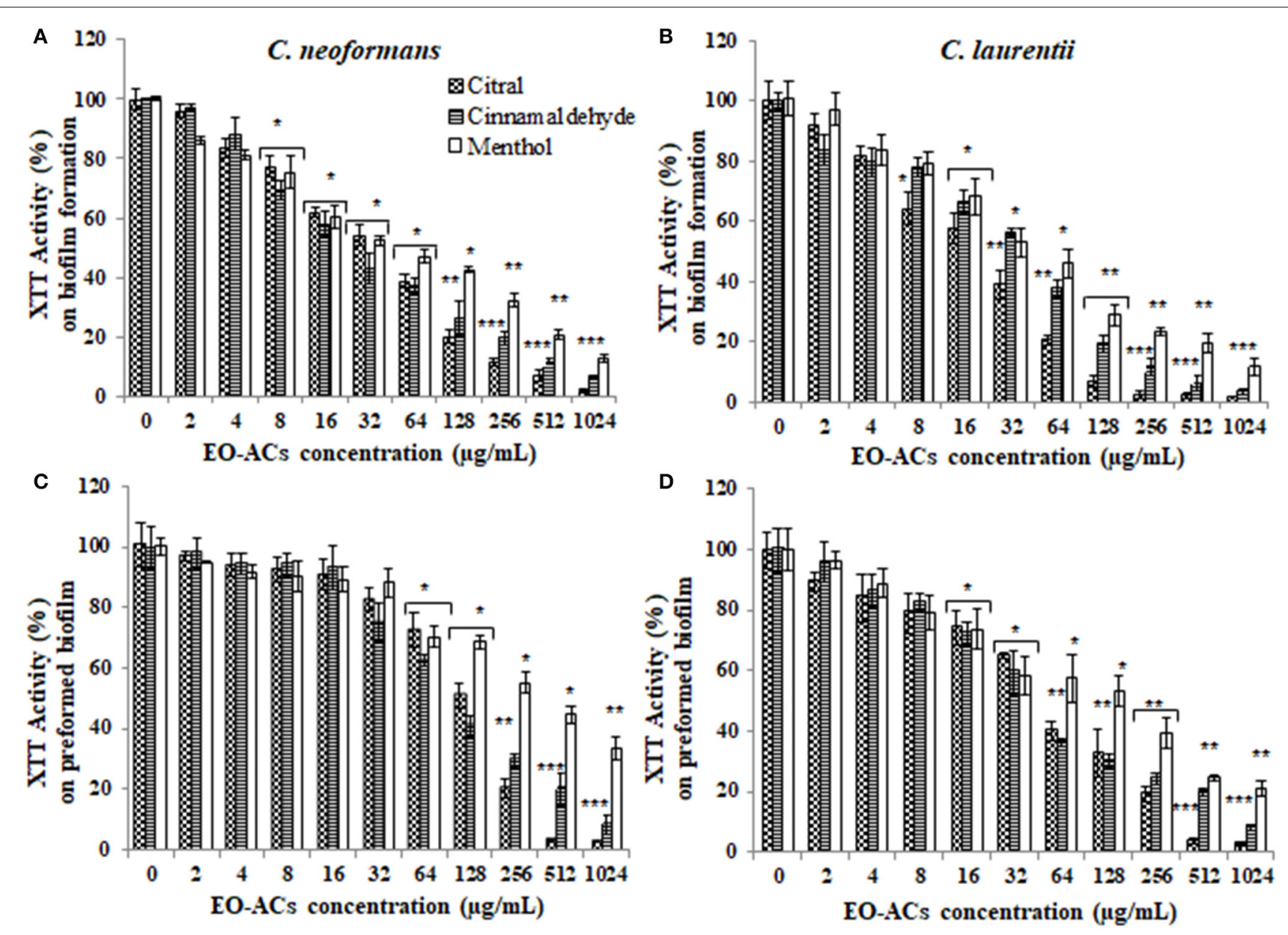

FIGURE 2 | Effect of terpenic aldehyde and alcohol (citral, menthol, and cinnamaldehyde) on C. neoformans and C. laurentii (A,B) biofilm formation (C,D) preformed biofilms. Results represent average \% metabolic activity \pm SD. ${ }^{*} p<0.05,{ }^{* *} p<0.01,{ }^{* \star *} p<0.001$ when compared with control.

controls (Figures 6A, 7A). The results suggested that among the above EO-ACs; thymol exhibited the minimum cytotoxicity while citral showed the maximum cytotoxic activity against both the human cell lines.

\section{Bright-Field and Fluorescence Microscopic Analysis of HEK-293 and HaCaT}

The bright field images of HEK293 cells and HaCaT cells after treatment at respective $\mathrm{MIC}_{80}$ of the three EO-ACs for $24 \mathrm{~h}$, showed no morphological alteration in response to the thymol and carvacrol treatment whereas little morphological disruption were visible in the citral treated cells (Figures 6B, 7B). These results were well supported by the fluorescence micrographs of HEK-293 and HaCaT cells labeled by fluorescent probes AO/EB. The AO dye is permeable to both live and dead cells and stains all nucleated cells to generate green fluorescence while the EB stains cells that have lost membrane integrity and thus emit red fluorescence (Mohapatra et al., 2017). In combination, apoptotic cells stain yellowish orange and necrotic cells stain reddish orange. Dual staining confirmed that the control group, thymol, and carvacrol treated groups showed the maximum number of AO stained viable human cells with normal cellular morphology whereas citral treated cells showed some EB stained cells as an indication of apoptosis/cytotoxicity (Figures 6B, 7B).

\section{Evaluating the Efficacy of EO-ACs in Co-culture Model of Cryptococcus sp. and HaCaT}

The EO-ACs efficacy at their respective $\mathrm{MIC}_{80}$ values to prevent cutaneous cryptococcosis was evaluated using a co-culture model of human keratinocytes; HaCaT infected with C. neoformans and C. laurentii. The co-culture model was also helpful in visualizing a real model of cryptococcal cells coexisting with keratinocytes incubated with the tested EO-ACs. The brightfield micrographs showed vehicle control (0.1\% DMSO) with uniformly dispersed cryptococcal cells along with $\mathrm{HaCaT}$ cells (Figures 8A,B). The corresponding fluorescence micrographs allowed for a qualitative assessment of the distribution of live cryptococcal cells (green color) with respect to live (green color) and dead (red color) 


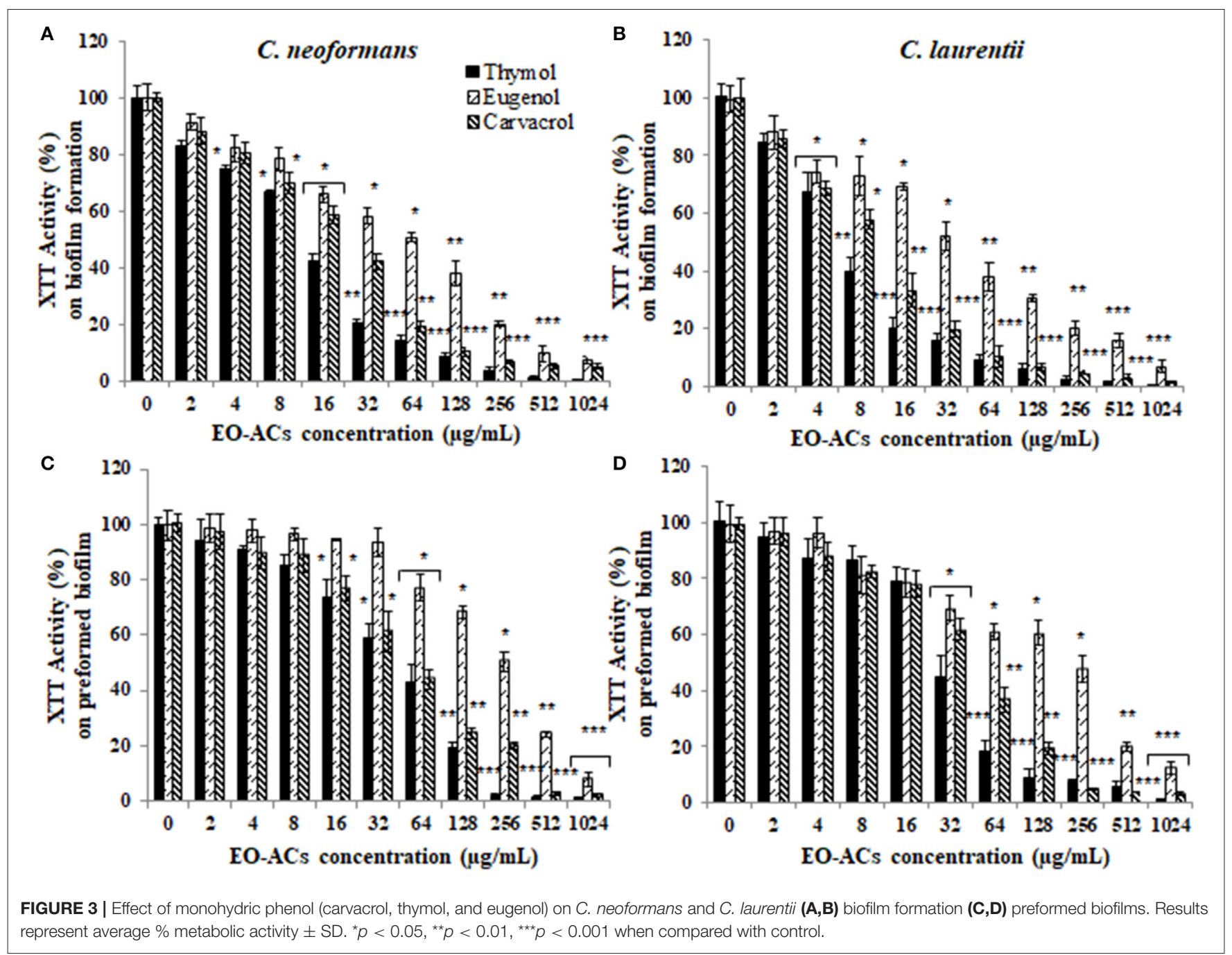

keratinocytes (Figures 8A,B). Co-culture model treated with EOACs showed sparse and uneven accumulation of $C$. neoformans and C. laurentii (red color) compared to the control. Thymol and carvacrol treated cryptococcal cells were observed to be dead and stained red with $\mathrm{EB}$ while, most of the $\mathrm{HaCaT}$ cells stained green with $\mathrm{AO}$ indicating the specific action of the EO-ACs toward C. neoformans and C. laurentii. However, at $\mathrm{MIC}_{80}$ of citral, apoptosis of both, the cryptococcal cells and some of the HaCaT cells were observed.

\section{DISCUSSION}

In recent years, a major concern associated with managing cryptococcosis is the emergence of antimicrobial resistant strains of $C$. neoformans and C. laurentii along with their competence to form recalcitrant biofilms in medical settings (Ajesh and Sreejith, 2012; Smith et al., 2015). The ability of fungi to develop such resistance against a drug is an evolutionary process and cannot be abrogated (Srinivasan et al., 2014).
Therefore, it has become indispensable to identify/develop a novel class of drugs that are natural and directed against targets which do not impart selective pressure or promote drug-resistance. In this regard, EO-ACs offers a great potential for developing novel broad-spectrum key molecules against a wide range of drug-resistant pathogenic microbes (Swamy et al., 2016). Recently, Cardoso et al. (2016) and Cavaleiro et al. (2015) reported strong antifungal activity of EO-ACs of Ocimum basilicum (linalool and geraniol) and Angelica major ( $\alpha$-pinene and cis- $\beta$-ocimene) against $C$. neoformans and anti-biofilm activity against Candida species. Keeping this in view, the present study evaluated the holistic efficacy of six EO-ACs (thymol, carvacrol, eugenol, citral, cinnamaldehyde and menthol) against Cryptococcus sp. three infectious forms, i.e., planktonic, biofilm formation and preformed biofilm respectively.

Among the tested EO-ACs; thymol, carvacrol, and citral were selected based on criteria proposed by Morales et al. (2008) for an antimicrobial potential of products which considers a product with MIC: $<100 \mu \mathrm{g} / \mathrm{mL}$ to have strong antimicrobial 


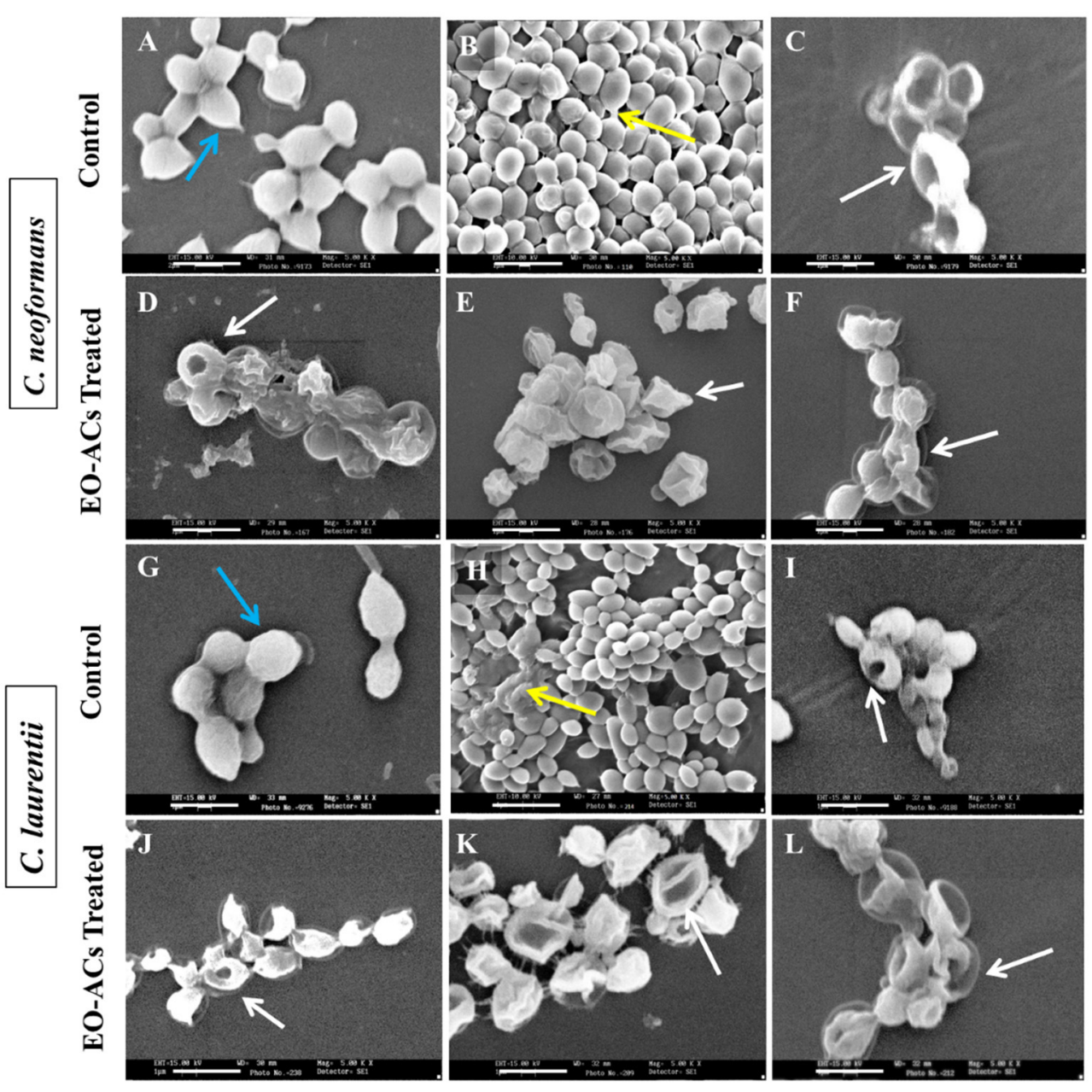

FIGURE 4 | Scanning electron microscopic images of C. neoformans and C. laurentii biofilm formed in the absence and presence of EO-ACs on polystyrene disc in 12-well culture plates at $30{ }^{\circ} \mathrm{C}$ for $48 \mathrm{~h}$. (A,G) Negative control: $1 \%$ DMSO + 10\% mineral oil (MO) at O h (B,H) biofilms after $48 \mathrm{~h}$ (C,I) Positive control: amphotericin B (4 and $2 \mu \mathrm{g} / \mathrm{mL}) \mathbf{( D , J ) ~ E O - A C s ~ t r e a t m e n t : ~ c i t r a l ~ ( 1 2 8 ~ a n d ~} 64 \mu \mathrm{g} / \mathrm{mL})(\mathbf{E}, \mathbf{K})$ carvacrol (64 and $32 \mu \mathrm{g} / \mathrm{mL})$ and $(\mathbf{F}, \mathbf{L})$ thymol $(32$ and $16 \mu \mathrm{g} / \mathrm{mL})$. In the control panel; Blue arrows indicate normal cells with a smooth surface and yellow arrows show extracellular polymeric matrix (EPM) of biofilm, while in treatment panel; white arrows indicate structural and morphological changes after treatment. Magnification 5000X, bar $1 \mu \mathrm{m}$.

activity. Thymol was the most effective EO-ACs which efficiently inhibited Cryptococcus sp; planktonic cells, biofilm formation and mature biofilms (Table 1, Figure 3). Its activity was closely followed by that of carvacrol and citral (Figures 2, 3). Even though, the standard drugs (amphotericin B, nystatin) used in the present study inhibited the planktonic form of the cryptococcal cells at a much lower concentration ( 1 and $2 \mu \mathrm{g} / \mathrm{mL}$ ) than the EO-ACs, however when evaluated for their efficacy against biofilm forms, the $\mathrm{BEC}_{80}$ values were 32-64 times higher than its $\mathrm{MIC}_{80}$ values. On the other hand, the $\mathrm{BEC}_{80}$ of thymol, carvacrol, and citral against preformed biofilm were only 48 -fold higher than planktonic cells (Table 1). These results suggested that the biofilms of $C$. neoformans and C. laurentii were significantly more susceptible to the terpenic compounds in comparison to the standard drugs. The study also revealed that the biofilm of $C$. laurentii was more susceptible to the EO-ACs in comparison to C. neoformans, which was in line with a similar study on biofilms of Candida albicans and nonalbicans species demonstrating the presence of species-specific and drug-specific differences respectively (Simitsopoulou et al., 2013).

Such antifungal and anti-biofilm activity of thymol (monoterpenoid found in the thyme oil) can be attributed to its structure 2-isopropyl-5-methylphenol (Borugă et al., 2014). The in vitro findings of the study was confirmed with the SEM and confocal images of cells treated with thymol which showed a significant reduction in the number of cells with deformed and perforated outer membrane (Figures 4, 5). These morpho-structural alterations of cells and its damage are more likely due to penetration of thymol into cell membrane outer layer resulting in expansion of dipalmitoyl-phosphatidylcholine (DPPC) monolayers. This causes a decrease in surface elasticity and thereby changing the lipid bilayer morphology which leads to extreme 


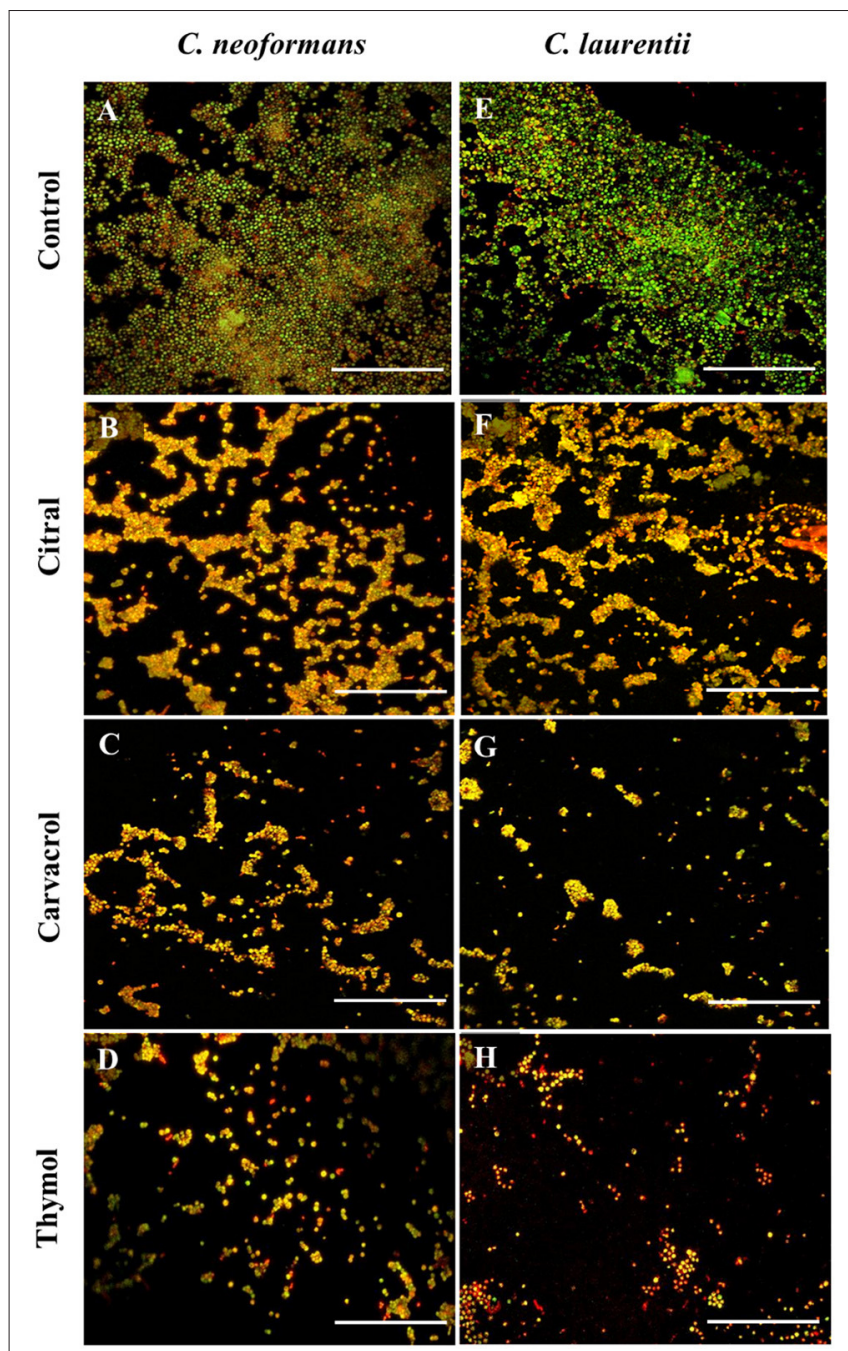

FIGURE 5 | Confocal laser scanning microscopic images of $C$. neoformans and C. laurentii biofilms formed before and after treatment with EO-ACs. (A,E) Control (1\% DMSO) (B-D) $32 \mu \mathrm{g} / \mathrm{ml}$ of citral, carvacrol and thymol (F-H) $16 \mu \mathrm{g} / \mathrm{ml}$ of citral, carvacrol and thymol. In the control panels, images of biofilm showed metabolically active (red, FUN-1-stained) cells embedded in the EPM (green, CAAF- 488 -stained). In the citral, carvacrol and thymol treatment panels, the yellow-brownish region represents metabolically non-viable cells. The images were taken by using 40X power field. Scale bar $50 \mu \mathrm{m}$.

rapid efflux of intracellular constituents (Ferreira et al., 2016).

Carvacrol [2-Methyl-5-(propan-2-yl) phenol] is found alone or in combination with its isomer thymol in oregano and thyme oil (Nostro et al., 2007). The effective concentration of carvacrol against planktonic and biofilm forms of Cryptococcus sp. was 2-fold higher than thymol (Table 1). Various different mechanism of action have been proposed for carvacrol which includes $\mathrm{Ca}^{2+}$ stress and inhibition of the TOR (Target of Rapamycin) pathway resulting in the formation of lesions on the membrane thereby blocking the ergosterol biosynthesis leading to the damage of enzymatic cell systems involved in energy production and synthesis of structural compounds (Suntres
TABLE 2 | Evaluation of cytotoxic concentration of thymol, carvacrol, and citral on normal HaCaT and HEK-293 cells.

\begin{tabular}{lcr}
\hline EO-ACs Treatment & \multicolumn{2}{c}{ Cytotoxicity $\mathbf{C C}_{\mathbf{5 0}}(\boldsymbol{\mu} \mathbf{g} / \mathbf{m L})$} \\
\cline { 2 - 3 } & \multicolumn{1}{c}{ HaCaT } & HEK-293 \\
\hline Thymol & $1,280.00 \pm 3.11$ & $283.65 \pm 2.45$ \\
Carvacrol & $154.82 \pm 2.16$ & $113.00 \pm 2.05$ \\
Citral & $93.20 \pm 1.96$ & $57.41 \pm 1.75$
\end{tabular}

The $C_{50}$ values are mean $\pm S D$ of three independent experiments $(p<0.05)$.

et al., 2015). Recently Chaillot et al. (2015) reported that carvacrol acts as an antifungal agent by changing endoplasmic reticulum (ER) integrity causing ER stress and induction of the unfolded protein response (UPR). All these modes in synergy or individually can affect the membrane integrity of the fungal cell(s).

Lastly, citral (3,7-dimethyl-2-6-octadienal) is a mixture of geranial (citral A) and neral (citral B) which naturally occurs in lemongrass oil (Silva et al., 2008). Few authors have previously reported the antifungal activity of citral against planktonic cells of C. neoformans (Viollon and Chaumont, 1994; Lima et al., 2005). The present study displayed that the concentration of citral required to inhibit biofilm formation $\left(\mathrm{BIC}_{80}\right)$ and eradicate preformed biofilm $\left(\mathrm{BEC}_{80}\right)$ was 2 and 4-fold higher compared to carvacrol and thymol respectively (Figures 2, 3). The morphological observation in case of citral against Cryptococcus sp. was supported by a similar study reporting the action of lemongrass oil rich in citral against $C$. albicans which caused deleterious changes in cell surface and structure (Tyagi and Malik, 2010). Citral mainly targets fungal cell membrane by blocking its synthesis and affecting membrane structure by inhibiting spore germination, proliferation and cellular respiration (Harris, 2002). However, its mechanism of action does not involve cell wall or ergosterol (Leite et al., 2014). Considering the fact that immunocompromised individuals are the most vulnerable host to a number of pathogenic infection. The present study was compared with the previous studies carried out on pathogenic fungi (Candida sp.) and other bacterial species (Staphylococcus sp., Klebsiella sp., Pseudomonas sp., Acetinobacter sp.) (Table 3). The comparison showed the broad spectrum potential of thymol, carvacrol, and citral against the above listed biofilm forming micro-organisms, illustrating the significance of using these EO-ACs for developing universal drug therapies.

However, to fully realize the potency of thymol, carvacrol, and citral, the study also evaluated their toxicity against the human cell lines HaCaT and HEK-293 using in vitro model. The fungal and humans cells are eukaryotic and being similar in nature poses a major hurdle in antifungal development. Thus, fungusspecific drug targets to avoid undesirable cytotoxicity to human cells are required (Krcmery and Kalavsky, 2007). Data showed that the $\mathrm{CC}_{50}$ of thymol and carvacrol for HaCaT was 80-160 and 10-20-folds higher while for HEK-293 it was 18-35 and 7-14-folds higher than its $\mathrm{MIC}_{80}$ against $C$. neoformans and 


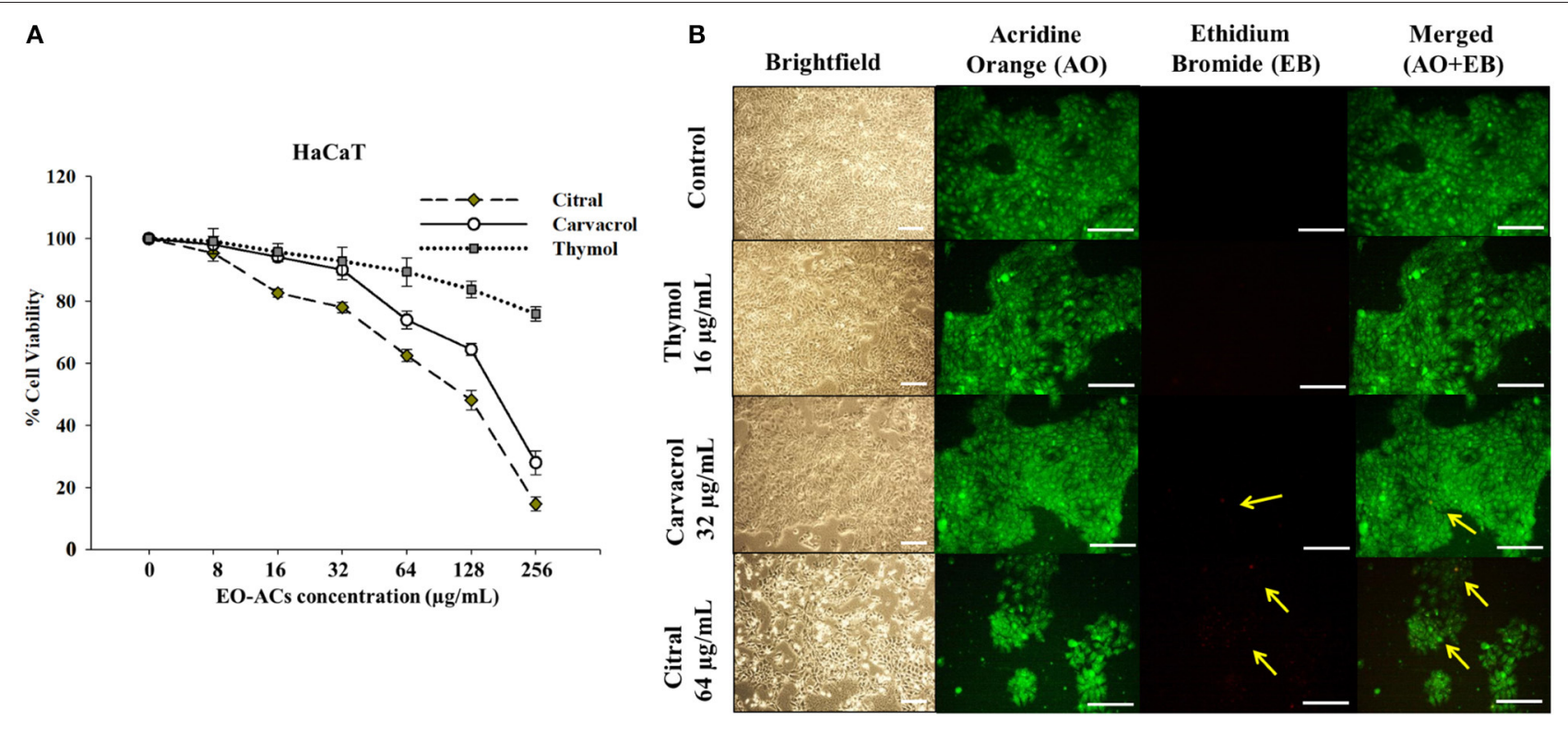

FIGURE 6 | Cytotoxic effects of EO-ACs on HaCaT. (A) The cytotoxic effect of thymol, carvacrol, and citral on normal human keratinocytes viability (B) Brightfield and fluorescence microscopy of $\mathrm{HaCaT}$ cells before and after treatment with thymol, carvacrol, and citral at their respective $\mathrm{MIC}_{80} \mathrm{Control}_{\mathrm{ind}}$ treatment panels show fluorescence images stained with acridine orange and ethidium bromide for live/dead cells (Green: live cells and Red: dead cells). Yellow arrows indicate dead keratinocytes. The brightfield images were taken using 10X power field and fluorescence images were taken using $40 \mathrm{X}$ power field. Scale bar $50 \mu \mathrm{m}$.

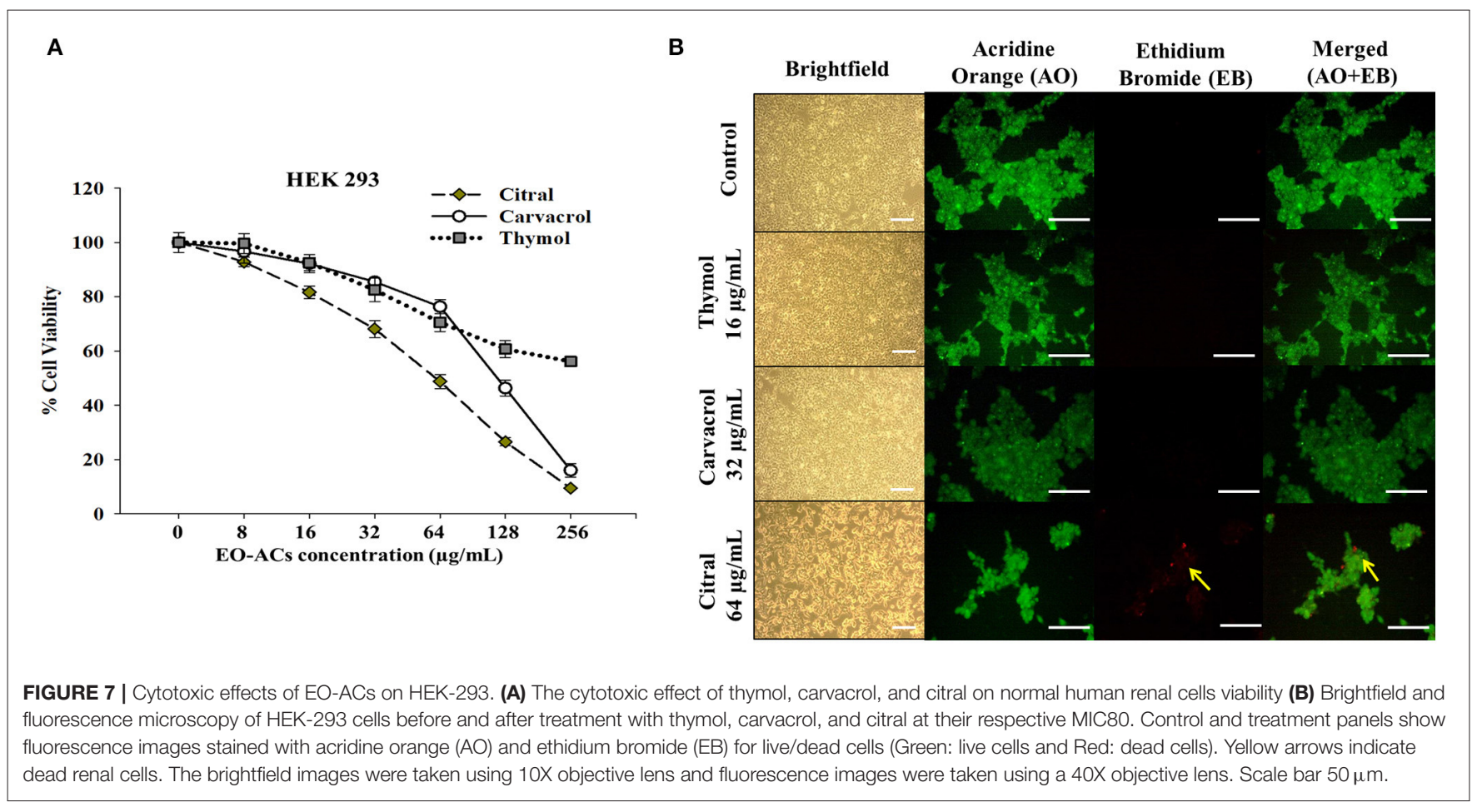

C. laurentii respectively. This suggested that there is a range of concentrations at which these two EO-ACs could be used as an antifungal agent without causing significant toxicity to human cells (Table 2). However, the $\mathrm{CC}_{50}(57.4$ and $93.2 \mu \mathrm{g} / \mathrm{mL}$ ) of citral against the above two cell lines was comparable to its
$\mathrm{MIC}_{80}$ rendering it cytotoxic to humans. The above findings corroborated with a previous study that proves thymol and carvacrol as the safe option while do not recommend citral as potential therapeutic agent (Elshafie et al., 2017). Additionally, the above results were supported by fluorescence microscopy of 

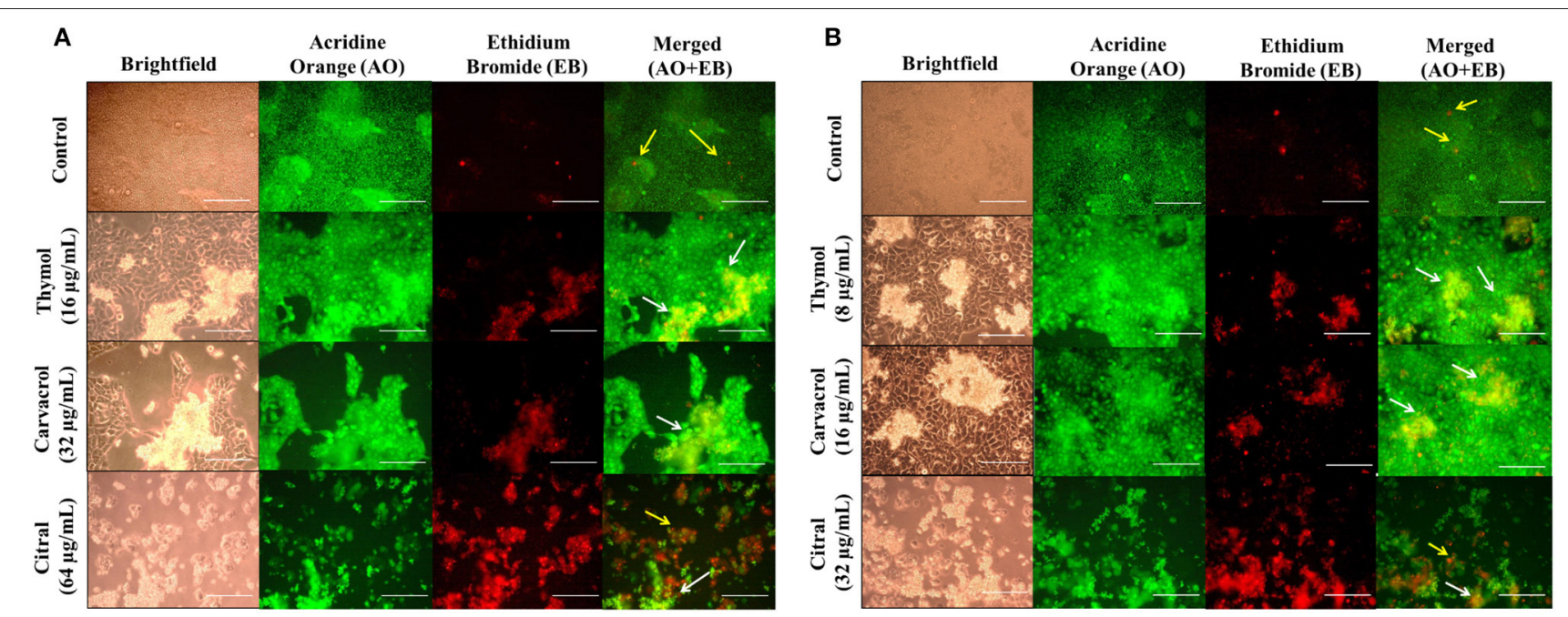

FIGURE 8 | Effect of EO-ACs (thymol, carvacrol, and citral) treatment in Cryptococcus-HaCaT coculture model (A) C. neoformans (B) C. laurentii. The viability of co-cultured HaCaT and cryptococcal cells in the presence of EO-ACs was assessed by fluorescence microscopy using AO-EB dual staining. Control panel shows uniformly dispersed live cryptococcal cells (green, AO stained) with few dead HaCaT cells (red, EB stained). Thymol and carvacrol treatment panel show live HaCaT (green) and sparse and unevenly distributed dead cryptococcal cells (red). Citral treatment panels show dead cryptococcal cell with necrotic HaCaT cells. Yellow arrows indicate dead keratinocytes and the white arrow indicate dead cryptococcal cells. The brightfield and fluorescence images were taken using a $40 \mathrm{X}$ objective lens. Scale bar $50 \mu \mathrm{m}$.

TABLE 3 | Comparative analysis of antimicrobial and anti-biofilm potential of thymol, carvacrol and citral against biofilm forming micro-organisms.

\begin{tabular}{|c|c|c|c|c|c|c|c|c|c|c|}
\hline \multirow[t]{3}{*}{ MicroOrganisms (Strain) } & \multicolumn{10}{|c|}{ Essential Oil Active Components (EO-ACs) $(\mu \mathrm{g} / \mathrm{ml})$} \\
\hline & \multicolumn{3}{|c|}{ Thymol } & \multicolumn{3}{|c|}{ Carvacrol } & \multicolumn{3}{|c|}{ Citral } & \multirow[t]{2}{*}{ References } \\
\hline & MIC & BIC & BEC & MIC & BIC & BEC & MIC & BIC & BEC & \\
\hline Stapylococcus aureus $\left(6 \mathrm{ME}^{\mathrm{a}}\right.$, ATCC $\left.6538^{\mathrm{b}}\right)$ & $300^{a}$ & $600^{\mathrm{a}}$ & $2,500^{a}$ & $100^{a}$ & $600^{a}$ & $2,500^{a}$ & $500^{b}$ & $500^{b}$ & $1,000^{b}$ & Nostro et al., 2007 \\
\hline Stapylococcus epidermidis (ATCC 35984) & 600 & 1,250 & 5,000 & 300 & 1,250 & 5,000 & - & - & - & Nostro et al., 2007 \\
\hline Klebsiella pneumoniae (OXA-48) & 200 & 200 & - & 125 & 125 & - & - & - & - & Raei et al., 2017 \\
\hline Pseudomonas aeruginosa (GIM) & 800 & 800 & - & 250 & 500 & - & - & - & - & Raei et al., 2017 \\
\hline Acetinobacter baumanni (SIM) & 200 & 400 & - & 62 & 250 & - & - & - & - & Raei et al., 2017 \\
\hline Candida albicans (ATCC 66396 ${ }^{d}, 04^{d}$ ) & $100^{C}$ & - & $300^{C}$ & $97.6^{\mathrm{C}}$ & - & $292.8^{C}$ & $148.62^{d}$ & - & $594^{d}$ & Dalleau et al., 2008 \\
\hline Candida glabrata (IHEM 9556 ${ }^{\mathrm{e}}$, ATCC $2001^{\mathrm{f}}$ ) & $200^{e}$ & - & $1,250^{\mathrm{e}}$ & $195.2^{\mathrm{e}}$ & - & $1,250^{\mathrm{e}}$ & $128^{f}$ & - & - & Dalleau et al., 2008 \\
\hline Candida parapsilosis (ATCC 22019) & 200 & - & 600 & 195.2 & - & 1,250 & 500 & - & 5,000 & Dalleau et al., 2008 \\
\hline Cryptococcus neoformans (NCIM 3541) & 16 & 32 & 128 & 32 & 64 & 256 & 64 & 128 & 256 & This study \\
\hline Cryptococcus laurentii (NCIM 3373) & 8 & 16 & 64 & 16 & 32 & 128 & 32 & 64 & 256 & This study \\
\hline
\end{tabular}

Data values ${ }^{a, b, c, d, e, f}$ corresponds to the tested strains; - not tested on the strain.

the co-culture model that showed a significant decrease in viable cryptococcal cells dispersed among keratinocytes in the presence of EO-ACs (Figures 8A,B). It is important to note that there were no morphological changes in the thymol and carvacrol treated $\mathrm{HaCaT}$ cells in comparison to the control cells. Further, the overall density and the distribution of live keratinocytes (green color) appeared similar to the control. However, citral treatment though killed cryptococcal cells but also resulted in a loss of $62.4 \%$ cell viability of keratinocytes, thereby making it unsafe for human usage (Figure 6A). Moreover, both carvacrol and thymol have been classified as GRAS (generally recognized as safe) and their use in food has been approved by European Parliament and Council (Hyldgaard et al., 2012) making them a potential option for developing anti-cryptococcal drugs.

\section{CONCLUSION}

To conclude, this is the first study exploring efficacy and safety of three EO-ACs; thymol, carvacrol, and thymol against $C$. neoformans and $C$. laurentii. The obtained results corroborated that thymol and carvacrol could be promising, efficient and cost-effective drugs for the inhibition of Cryptococcus biofilms. However, it is worthy to note that standard drugs showed antifungal and anti-biofilm activity at a lower concentration as compared to above EO-ACs but these concentrations are much beyond the therapeutic range causing severe toxicity. Hence future studies may investigate the efficacy of combinational therapy of EO-ACs with standard drugs or with other EO-ACs 
which could lead to novel drug therapies against recalcitrant infections.

\section{AUTHOR CONTRIBUTIONS}

PK and RP conceived and designed the experiments. AC and RG along with PK performed antimicrobial work. RM under the supervision of PR carried out cell culture work. PK analyzed the data and wrote the manuscript. RP and NA gave critical

\section{REFERENCES}

Ajesh, K., and Sreejith, K. (2012). Cryptococcus laurentii biofilms: structure, development and antifungal drug resistance. Mycopathologia 174, 409-419. doi: 10.1007/s11046-012-9575-2

Alves-Silva, J. M., Zuzarte, M., Gonçalves, M. J., Cavaleiro, C., Cruz, M. T., Cardoso, S. M., et al. (2016). New claims for wild carrot (Daucus carota subsp. carota) essential oil. Evid. Based Complement. Alternat. Med. 2016:9045196. doi: 10.1155/2016/9045196

Aslanyan, L., Sanchez, D., Valdebenito, S., Eugenin, E., Ramos, R., and Martinez, L. (2017). The crucial role of biofilms in Cryptococcus neoformans survival within macrophages and colonization of the central nervous system. J. Fungi 3:10. doi: 10.3390/jof3010010

Bakkali, F., Averbeck, S., Averbeck, D., and Idaomar, M. (2008). Biological effects of essential oils-a review. Food Chem. Toxicol. 46, 446-475. doi: $10.1016 /$ j.fct.2007.09.106

Berger, S. (2017). Cryptococcosis: Global Status. Gideon E-Book Series. Los Angeles, CA: Gideon Informatics, Inc.

Borugă, O., Jianu, C., Mişcă, C., Golet, I., Gruia, A. T., and Horhat, F. G. (2014). Thymus vulgaris essential oil: chemical composition and antimicrobial activity. J. Med. Life 7, 56-60.

Brouwer, A. E., Rajanuwong, A., Chierakul, W., Griffin, G. E., Larsen, R. A., White, N. J., et al. (2004). Combination antifungal therapies for HIVassociated cryptococcal meningitis: a randomised trial. Lancet 363, 1764-1767. doi: 10.1016/S0140-6736(04)16301-0

Cardoso, N. N. R., Alviano, C. S., Blank, A. F., Romanos, M. T. V., Fonseca, B. B., Rozental, S., et al. (2016). Synergism effect of the essential oil from Ocimum basilicum var. Maria Bonita and its major components with fluconazole and its influence on ergosterol biosynthesis. Evid. Based Complement. Alternat. Med. 2016:5647182. doi: 10.1155/2016/5647182

Cavaleiro, C., Salgueiro, L., Goncalves, M. J., Hrimpeng, K., Pinto, J., and Pinto, E. (2015). Antifungal activity of the essential oil of Angelica major against Candida, Cryptococcus, Aspergillus and dermatophyte species. J. Nat. Med. 69, 241-248. doi: 10.1007/s11418-014-0884-2

Chaillot, J., Tebbji, F., Remmal, A., Boone, C., Brown, G. W., Bellaoui, M., et al. (2015). The monoterpene carvacrol generates endoplasmic reticulum stress in the pathogenic fungus Candida albicans. Antimicrob. Agents Chemother. 59, 4584-4592. doi: 10.1128/AAC.00551-15

CLSI (2008). Reference Method for Broth Dilution Antifungal Susceptibility Testing of Yeasts, Approved Standard, 3rd Edn, M27-A3. Wayne: Clinical and Laboratory Standards Institute.

Dalleau, S., Cateau, E., Berges, T., Berjeaud, J. M., and Imbert, C. (2008). In vitro activity of terpenes against Candida biofilms. Int. J. Antimicrob. Agents 31, 572-576. doi: 10.1016/j.ijantimicag.2008.01.028

Darwish, M. S. A., Cabral, C., Goncalves, M. J., , Cavaleiro, C., Cruz, M. T., Paoli, M., et al. (2016). Ziziphora tenuior L. essential oil from Dana Biosphere Reserve (Southern Jordan); Chemical characterization and assessment of biological activities. J. Ethnopharmacol. 194, 963-970. doi: 10.1016/j.jep.2016. 10.076

Delattin, N., Cammue, B., and Thevisse, K. (2014). Reactive oxygen speciesinducing antifungal agents and their activity against fungal biofilms. Future Med. Chem. 6, 77-90. doi: 10.4155/fmc.13.189

Elshafie, H. S., Armentano, M. F., Carmosino, M., Bufo, S. A., Feo, V. D., and Camele, I. (2017). Cytotoxic activity of Origanum vulgare L. on hepatocellular revisions of intellectual content along with final approval for publication.

\section{ACKNOWLEDGMENTS}

The authors are thankful for the financial support in the form of fellowship [Grant no: 09/143(0857, 0858)/2014-EMR-I] to PK and AC from Council of Scientific and Industrial Research, (CSIR), New Delhi, India. carcinoma cell line HepG2 and evaluation of its biological activity. Molecules 22:1435. doi: 10.3390/molecules22091435

Ferreira, J. V. N., Capello, T. M., Siqueira, L. J. A., Lago, J. H. G., and Caseli, L. (2016). Mechanism of action of thymol on cell membranes investigated through lipid Langmuir monolayers at the air-water interface and molecular simulation. Langmuir 32, 3234-3241. doi: 10.1021/acs.langmuir.6b00600

Fontenelle, R. O., Morais, S. M., Brito, E. H., Kerntopf, M. R., , Brilhante, R. S., Cordeiro, R. A., et al. (2007). Chemical composition, toxicological aspects and antifungal activity of essential oil from Lippia sidoides Cham. J. Antimicrob. Chemother. 59, 934-940. doi: 10.1093/jac/dkm066

Harris, R. (2002). Progress with superficial mycoses using essential oils. Int. J. Aromather. 12, 83-91. doi: 10.1016/S0962-4562(02)00032-2

Hyldgaard, M., Mygind, T., and Meyer, R. L. (2012). Essential oils in food preservation: mode of action, synergies, and interactions with food matrix components. Front. Microbiol. 3:12. doi: 10.3389/fmicb.2012.00012

Kasibhatla, S., Mendes, G. P. A., Finucane, D., Brunner, T., Wetzel, E. B., and Green, D. R. (2006). Acridine Orange/Ethidium Bromide (AO/EB) Staining to Detect Apoptosis. Cold Spring Harb. Protoc. 2006:pdb.prot4493. doi: $10.1101 /$ pdb.prot 4493

Khawcharoenporn, T., Apisarnthanarak, A., and Mundy, L. M. (2007). Nonneoformans cryptococcal infections: a systemic review. Infection 35, 51-58. doi: 10.1007/s15010-007-6142-8

Krcmery, V., and Kalavsky, E. (2007). Antifungal drug discovery, six new molecules patented after 10 years of feast: why do we need new patented drugs apart from new strategies? Recent Pat. Antiinfect. Drug Discov. 2, 182-187. doi: $10.2174 / 157489107782497317$

Kronstad, J. W., Attarian, R., Cadieux, B., Choi, J., D’Souza, C. A., Griffiths, E. J., et al. (2011). Expanding fungal pathogenesis: cryptococcus breaks out of the opportunistic box. Nat. Rev. Microbiol. 9, 193-203. doi: 10.1038/nrmicro2522

Leite, M. C. A., Bezerra, A. P., Sousa, J. P., Guerra, F. Q. S., and Lima, E. O. (2014). Evaluation of antifungal activity and mechanism of action of citral against Candida albicans. J. Evid. Based Complementary Altern. Med. 11, 1-9. doi: 10.1155/2014/378280

Lima, I. O., Oliveira, R. A. G., Lima, E. O., Souza, E. L., Farias, N. P., and Navarro, D. F. (2005). Inhibitory effect of some phytochemicals in the growth of yeasts potentially causing opportunistic infections. Braz. J. Pharm. Sci. 41, 199-203. doi: 10.1590/S1516-93322005000200007

Martinez, L. R., and Casadevall, A. (2005). Specific antibody can prevent fungal biofilm formation and this effect correlates with protective efficacy. Infect. Immun. 73, 6350-6362. doi: 10.1128/IAI.73.10.6350-6362.2005

Martinez, L. R., and Casadevall, A. (2006). Susceptibility of Cryptococcus neoformans biofilms to antifungal agents in vitro. Antimicrob. Agents Chemother. 50, 1021-1033. doi: 10.1128/AAC.50.3.1021-1033.2006

Martinez, L. R., and Casadevall, A. (2007). Cryptococcus neoformans biofilm formation depends on surface support and carbon source and reduces fungal cell susceptibility to heat, cold, and UV light. Appl. Environ. Microbiol. 73, 4592-4601. doi: 10.1128/AEM.02506-06

Martinez, L. R., and Casadevall, A. (2015). Biofilm formation by Cryptococcus neoformans. Microbiol Spectr. 3, 1-11. doi: 10.1128/microbiolspec.MB-0006-2014

Mohapatra, S., Mishra, R., Roy, P., Yadav, K. L., and Satapathi, S. (2017). Systematic investigation and in vitro biocompatibility studies on implantable magnetic nanocomposites for hyperthermia treatment of osteoarthritic knee joints. $J$. Mater. Sci. 52, 9262-9268. doi: 10.1007/s10853-017-1136-0 
Morales, G., Paredes, A., Sierra, P., and Loyola, L. A. (2008). Antimicrobial activity of three Baccharis species used in the traditional medicine of Northern Chile. Molecules 13, 790-794. doi: 10.3390/molecules 13040790

Nobrega, R. O., Teixeira, A. P., Oliveira, W. A., Lima, E. O., and Lima, I. O. (2016). Investigation of the antifungal activity of carvacrol against strains of Cryptococcus neoformans. Pharm. Biol. 54, 2591-2596. doi: 10.3109/13880209.2016.1172319

Nostro, A., Roccaro, A. S., Bisignano, G., Marino, A., Cannatelli, M. A., Pizzimenti, F. C., et al. (2007). Effects of oregano, carvacrol and thymol on Staphylococcus aureus and Staphylococcus epidermidis biofilms. J. Med. Microbiol. 56, 519-523. doi: 10.1099/jmm.0.46804-0

Park, B. J., Wannemuehler, K. A., Marston, B. J., Govender, N., Pappas, P. G., and Chiller, T. M. (2009). Estimation of the current global burden of cryptococcal meningitis among persons living with HIV/AIDS. AIDS 23, 525-530. doi: 10.1097/QAD.0b013e328322ffac

Raei, P., Pourlak, T., Memar, M. Y., Alizadeh, N., Aghamali, M., and Zeinalzadeh, E., et al. (2017). Thymol and carvacrol strongly inhibit biofilm formation and growth of carbapenemase-producing Gram negative bacilli. Cell. Mol. Biol. 63, 108-112. doi: $10.14715 / \mathrm{cmb} / 2017.63 .5 .20$

Ramage, G., and Williams, C. (2013). The clinical importance of fungal biofilms. Adv. Appl. Microbiol. 84, 27-83. doi: 10.1016/B978-0-12-407673-0.00002-3

Rizk, J. M. A., Falkler, W. A., and Meiller, T. F. (2004). Fungal biofilms and drug resistance. Emerg. Infect. Dis. 10, 14-19. doi: 10.3201/eid1001. 030119

Shorman, M., Evans, D., Gibson, C., and Perfect, J. (2016). Cases of disseminated cryptococcosis in intravenous drug abusers without HIV infection: a new risk factor? Med. Mycol. Case Rep. 14, 17-19. doi: 10.1016/j.mmcr.2016.12.003

Silva, C. D. B., Guterres, S. S., Weisheimer, V., and Schapoval, E. E. S. (2008). Antifungal activity of the lemongrass oil and citral against Candida spp. Braz. J. Infect. Dis. 12, 63-66. doi: 10.1590/S1413-867020080001 00014

Simitsopoulou, M., Peshkova, P., Tasina, E., Katragkou, A., Kyrpitzi, D., Velegraki, A., et al. (2013). Species-specific and drug-specific differences in susceptibility of Candida biofilms to echinocandins: characterization of less common bloodstream isolates. Antimicrob. Agents Chemother. 57, 2562-2570. doi: 10.1128/AAC.02541-12

Smith, K. D., Achan, B., Hullsiek, K. H., McDonald, T. R., Okagaki, L. H., and Alhadab, A. A. (2015). Increased antifungal drug resistance in clinical isolates of Cryptococcus neoformans in Uganda. Antimicrob. Agents Chemother. 59, 7197-7204. doi: 10.1128/AAC.01299-15

Srinivasan, A., Ribot, J. L. L., and Ramasubramanian, A. K. (2014). Overcoming antifungal resistance. Drug Discov. Today Technol. 11, 1-116. doi: 10.1016/j.ddtec.2014.02.005

Suntres, Z. E., Coccimiglio, J., and Alipour, M. (2015). The bioactivity and toxicological actions of carvacrol. Crit. Rev. Food Sci. Nutr. 55, 304-318. doi: 10.1080/10408398.2011.653458

Swamy, M. K., Akhtar, M. S., and Sinniah, U. R. (2016). Antimicrobial properties of plant essential oils against human pathogens and their mode of action: an updated review. Evid. Based Complement. Alternat. Med. 2016:3012462. doi: 10.1155/2016/3012462

Tampieri, M. P., Galuppi, R., Macchioni, F., Carelle, M. S., Falcioni, L. Cioni, P. L., et al. (2005). The inhibition of Candida albicans by selected essential oils and their major components. Mycopathologia 159, 339-345. doi: 10.1007/s11046-003-4790-5

Tyagi, A. K., and Malik, A. (2010). In situ SEM, TEM and AFM studies of the antimicrobial activity of lemon grass oil in liquid and vapour phase against Candida albicans. Micron 41, 797-805. doi: 10.1016/j.micron.2010.05.007

Viollon, C., and Chaumont, J. P. (1994). Antifungal properties of essential oils and their main components upon Cryptococcus neoformans. Mycopathologia 128, 151-153. doi: 10.1007/BF01138476

Wong, S. S. W., Kao, R. Y. T., Yuen, K. Y., Wang, Y., Yang, D., Samaranayake, L. P., et al. (2014). In vitro and in vivo activity of a novel antifungal small molecule against Candida infections. PLoS ONE 9:e85836. doi: 10.1371 /journal.pone.0085836

Conflict of Interest Statement: The authors declare that the research was conducted in the absence of any commercial or financial relationships that could be construed as a potential conflict of interest.

Copyright (c) 2017 Kumari, Mishra, Arora, Chatrath, Gangwar, Roy and Prasad. This is an open-access article distributed under the terms of the Creative Commons Attribution License (CC BY). The use, distribution or reproduction in other forums is permitted, provided the original author(s) or licensor are credited and that the original publication in this journal is cited, in accordance with accepted academic practice. No use, distribution or reproduction is permitted which does not comply with these terms. 